\title{
Review
}

\section{Perceptions of Body Image and Obesity among Cross Culture: A Review}

\author{
Yamunadevi Puraikalan, PhD, RDN* \\ Assistant Professor, Nutrition Science Department, Dominican University, IL 60305, USA

\section{${ }^{*}$ Corresponding author} \\ Yamunadevi Puraikalan, PhD, RDN \\ Assistant Professor, Nutrition Science Department, Dominican University, IL 60305, USA
}

\section{Article information}

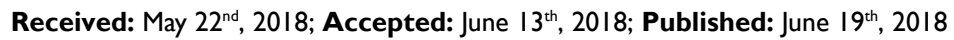

\section{Cite this article}

Puraikalan Y. Obesity: Perceptions of body image and obesity among cross culture:A Review. Obes Res Open J. 20I8; 5(I): I-4. doi: I0.17/40/OROJ-5-I33

\section{ABSTRACT}

Body image inconvenience is a common issue not only in the United States but also worldwide. The perception towards body image is basically subjective. There are also culture-specific notions in physical appearance. Prevalence of obesity seems to be greater among the African-Americans and other ethnic minority populations than Whites. According to Jansen, 2008 there is a relationship between body image and eating habits across the cultures. Many studies have found that Black women are more satisfied with their bodies than White women.

In the past, women always have been compared their bodies to celebrities, which could lead to depression and many negative consequences. Body image is a big concern among the individuals, especially in younger adults. Media had a high impact on dissatisfaction with physical body among the young adults. This leads to depression and many health problems. The significance of my review towards the field of dietetics could be to determine the perceptions of body image across cross-cultures and to determine the etiology of obesity. This could definitely shed some lights among the Registered Dietitians (RD) in terms of how body image is perceived by other cultures and aid in counseling them.

\section{Keywords}

Body Image; Obesity; Body dissatisfaction.
\end{abstract}

\section{INTRODUCTION}

P erception of physical appearance not only is common in United States, but is also present around the globe. The perception of body image is basically subjective and involves thoughts, emotions, and imaginations. There are also culture-specific notions about physical appearance. Body image is defined as "the multifaceted psychological experience of embodiment".

Body image (BI) usually consists of perception and attitudinal components ${ }^{2-4}$. Thus the feedback from others would determine the self-evaluation and perception of one's own body image satisfaction ${ }^{5}$. Therefore BI has a significant effect on one's life, self-esteem, personal happiness, and health. ${ }^{4}$ The perception of body weight is influenced by nutritional behavior and weight management among adolescents. ${ }^{6}$ The main barrier against reducing the prevalence of obesity is its cultural acceptability. ${ }^{7}$ Body weight perception may be influenced by maintaining an ideal body weight. In western society, slim is directly linked with self-control, beauty, youth, and attractiveness and women of higher socioeconomic status are less likely to be obese. ${ }^{8}$ The circumstances in some developing countries appear to be opposite and some studies conclude that obesity is admired and perceive as sexually desirable.

Self-perception of BI determines the satisfaction or dissatisfaction with one's own physique. ${ }^{9}$ In the recent years, there is raise in the literature for the BI and its psychology. This literature helps to determine the relationships between these themes and cultural variations.

Variables like self-esteem, socio-culture, peers, and family determine an individual's attitude and behavior. It's always the women being targeted to conform to being attractive. Women often lose or gain weight to maintain an ideal body weight. Research concludes that there is no correlation between women age and satisfaction of BI. Women mainly are concerned about the weight 


\section{Influence of Gender}

Previous studies determined that lower level of body satisfaction is more common among the female subjects in comparison with the male counterparts. Poor image is influenced by various factors like socialization, beauty expectations among cultures, ethnicity and profession, etc.

Gender also has its own influence on perception of BI. It is socio-culturally appropriate for males to maintain masculinity and females to maintain feminity. ${ }^{10}$ Gender role associates femininity with beauty and attractive appearance and masculinity with power and force. These assumptions have different effects on BI among two genders. Research shows that there are significant influences of gender in making health-related decisions. ${ }^{11,12}$ Women are more reluctant to visit a physician than men and they often experience a greater enjoyment in health-related information searches. Men are open towards a virtual patient-physician relationship.

According to Mahalik et al, ${ }^{13}$ perceptions of men's BI influenced their health behaviors. Similar research by Befort and Rickard $^{5}$ examined the effect of figure-size feedback on the BI, self-esteem and negative mood states of college men and women who were within normal body weight and without the symptoms of eating disorders. Women responded in accordance with the positive and negative valence of feedback whereas men were expected to show a positive bias in their response to the feedback.

It was found in a study that men and women who are underweight in their BMI seem to feel more satisfaction feelings of their BI than other groups. ${ }^{14}$ Among young people, body dissatisfaction is a particular concern. They have some specific preferences like slimness. Negative feelings about BI can seriously affect one's self-esteem and health, and they can also separate them from mingling with others. ${ }^{15}$

Eighty percent of women are not satisfied with their BI. ${ }^{16}$ Several researchers found that dieting is common in one's life at particular points to maintain a normal weight.

Women in the West are dissatisfied with their BI and coined the phrase "normative discontent" ${ }^{17}$ Research suggests that media also have an enormous effect on BI and are to be blamed for this view point. ${ }^{18}$ Among the non-westerners, the BI concerns were lesser when compared to that of Westerners. ${ }^{19}$ Media has an impact of BI among the younger generations in spite of Westernizations. $^{20}$

Self-perception of BI was more common to males because of the impact of media and magazines. Kolbe and Albanese $^{21}$ stated that the media targeted male models in the media industry and their financial situations. Yang, et $\mathrm{al}^{22}$ showed the rate of undressed male models in media is increased from 3\% to $35 \%$ in 1990's.

\section{Influence of Race}

The three main socio-cultural factors that influence BI are parents (mothers especially), peers and media. ${ }^{19}$ From these three sources, both genders obtain information pertaining to body shape and size. Exposure to media seems to have an effect on $\mathrm{BI} .{ }^{23}$ Women in the West is expected to have a good body figure and known as slim ideal. ${ }^{24}$ Slim women are found to be more successful and beautiful and have more self-esteem than overweight women. ${ }^{25}$ Because of the impact of media to maintain a thin frame, many women are exposed to negative feelings and they lower their self-control and confidence to get the desired weight. ${ }^{26}$ Stice et $\mathrm{al}^{27}$ found that media pressures women to be slim and it does not have a direct effect. In Middle Eastern countries, culture plays a vital role in preferences of body size among the children. These countries want their children to be heavier and highlighted them about the attractiveness of being overweight rather than slim. ${ }^{28}$

According to Abdollahi and Mann, ${ }^{29}$ Iranian women migrated to the United States seem to have a higher rate of eating disorders because of exposure to media and western culture. Whereas, the women living in Iran have very little knowledge about eating disorders.

Western nations seem to have more research on the correlation between eating habits and $\mathrm{BI}$ among cross-cultures. ${ }^{30} \mathrm{It}$ was concluded that countries other than the United States have lower BI rates and lesser prevalent in eating disorderse. ${ }^{30}$ Studies determine that Whites report more eating disturbance than nonWhites. ${ }^{31,32} \mathrm{BI}$ usually involves thoughts, perceptions, emotions and imagination. It does not necessarily reflect on the mirror. Poor $\mathrm{BI}$ often correlated with dieting, over-exercising or eating disorders and mental health issues.

\section{Black/White Differences in Perceived Weight}

Several studies have found that satisfaction about BI was higher among Black women than White women. They also have more self-esteem than White women. Powell and $\mathrm{Kahn}^{33}$ stated that White women expressed more concern than Black women with body weight and dieting. In general, Black men prefer females with heavier body more than White men do. Black women's satisfaction with their BI is higher to White women. ${ }^{34}$ When other external factors like age, weight and literacy level are controlled, culture does not have an influence on body shape and size or level of tolerance to being overweight. ${ }^{35}$ Several replication studies are still needed to confirm this hypothesis. ${ }^{34,} 35$ Many researchers have argued the disparities between Black and White BI are overstated.

Western nations seem to have more research on the correlation between eating habits and BI among cross-cultures. ${ }^{30} \mathrm{It}$ was concluded that countries other than the United States have lower BI rates and lesser prevalent in eating disorderse. ${ }^{30}$ Studies determine that Whites report more eating disturbance than nonWhites. ${ }^{31,32} \mathrm{BI}$ usually involves thoughts, perceptions, emotions, and imagination. It does not necessarily reflect on the mirror. Poor $\mathrm{BI}$ often correlated with dieting, over-exercising or eating disorders and mental health issues.

\section{BI and Ethnicity: BI and African-Americans}

Seventy percent of Black women are satisfied with their body weight and $90 \%$ of White women are satisfied with their body 
lese women. Int J Obes Relat Metab Disord. 2004; 28: 1561-1568. doi: 10.1038/sj.ijo.0802739

\section{BI and Hispanics}

Goodman ${ }^{37}$ stated that Hispanic women are satisfied with a heavier body weight. Pompper and Koenig ${ }^{38}$ found that media pressures them to be thin and slim. Viladrich, et $\mathrm{al}^{39}$ showed that both genders of Hispanics are now accepting a heavier BI. There are many conflicting studies about Hispanic women are more conscious of weight gain like White women. Viladrich, et $\mathrm{al}^{39}$ stated the results from their study consisting of 44 Hispanic women; overall they need a thin body frame due to media images.

\section{CONCLUSION}

In summarizing the literature on cultural influences on perception of body image, it is more important to recognize the changing nature of such ideals globally. Fewer studies have targeted on the etiology responsible to evaluate a negative and positive attitude about BI. It is important to focus research on all the populations about the perception of BI and their attitudes towards it. BI is the variance between ideal and current body sizes, understanding how body size ideals are shaped and transferred remains more important. Studies show that the largest differences in BI ideals are no longer found between western and non-western culture, however, it is found in socioeconomic status. More research on the perception of BI among Asian and American women is evidently needed.

\section{REFERENCES}

1. Cash TF, Pruzinsky T. Body Image: A Handbook of Theory,

Research, and Clinical Practice. New York, USA: Guilford Press: 2002.

2. Dolce JJ, Thompson JK, Register A, Spana RE. Generalization of body size distortion. Int J Eat Disord. 1987; 6:401408. doi: 10.1002/1098-108X(199101)10:1\%3C15::AIDEAT2260100103\%3E3.0.CO;2-I

3. Thompson JK, Altabe MN. Psychometric qualities of the Figure Rating Scale. Int J Eat Disord. 1991; 10:61-69.doi:10.1002/1098108X(199109)10:5\%3C615::AID-EAT2260100514\%3E3.0.CO;2K

4. Jestes DA. Body Image: How You See It, How You Don't. National Undergraduate Research Clearinghouse.1999. Website. http://www.webclearinghouse.net/volume/2/JESTES-BodyImageH.php. Accessed January 3, 2011

5. Befort CA, Rickard KM. Gender similarities in response to figure-size feedback in a selected non-clinical population. Sex Roles. 2003; 49: 71-80. doi: 10.1023/A:1023913720317

6. Brener ND, Eaton DK, Lowry R, Mamanus T. The association between weight perception and BMI among high students. Obes Res. 2004; 12:1866-1874. doi: 10.1038/oby.2004.232

7. Holdsworth M, Gartner A, Landais E, Maire B, Depleuch F. Perception of healthy and desirable body size in urban Senega-
8. Flynn K, Fitzgibbon BM. Body images and obesity risk among Black females: a review of literature. Ann Behav Med.1998; 20: 1324. doi: 10.1007/BF02893804

9. Hsu LKG, Sobkiewics TA. Body Image Disturbance: Time to abandon the concept for eating disorders?.Int J Eat Disord, 1991;10: 15-30. doi:10.1002/1098-108X(199101)10:1<15::AIDEAT2260100103>3.0.CO;2-I

10. Crawford M. Transformations: Women, Gender and Psychology. New York, USA: McGraw-Hill: 2006.

11. Von Bothmer M, Fridlund B. Gender Differences in Health Habits and in Motivation for a Healthy Lifestyle among Swedish University Students. Nursing \& Health Sciences. 2005; 7: 107. doi: 10.1111/j.1442-2018.2005.00227.x

12. Nolen-Hoesksema. Possible Contributors to the Gender Differences in Alcohol Use and Problems. J Gen Psychol. 2006; 133(4): 357-374. doi: 10.3200/GENP.133.4.357-374

13. Mahalik J, Burns S, Syzdeky M. Masculinity and perceived normative health as predictors of men's health behaviors. Soc Sci Med. 2007; 64: 2201-2209. doi: 10.1016/j.socscimed.2007.02.035

14. Sanchez-Villegas A, Madrigal H, Martinez- Gonzalez MA, Kearney J, Gibney MJ, de Irala J, JMartínez JA Perception of body image as indicator of weight status in the European Union. J Hum Nutr Diet. 2001; 14:93

15. Website. www.aihw.gov.au/reports/children-youth/youngaustralians-their-health-and-wellbeing. Accessed January 10, 2011.

\section{Nikki K. Your Guide to Women's issues,2005: 1}

17. Rodin J, Silberstein L, Striegel-Moore R. Women and weight: a normative discontent. Nebr Symp Motiv. 1985; 32: 267-307

18. Ruggiero GM, Hannover W, Mantero M, Papa R. Body acceptance and culture: A study in northern and southern Italy. Eur Eat Disord Rev. 2000; 8(1), 40-50. doi: 10.1002/(SICI)10990968(200002)8:1<40::AID-ERV327>3.0.CO;2-D

19. Lam TH, Lee SW, Fung S, Ho SY, Lee P,Stewart SM. Sociocultural influences on body dissatisfaction and dieting in Hong Kong girls. Eur Eat Disord Rev. 2009;17: 152-160

20. Xu X, Mellor D, Kiehne M, Ricciardelli LA, McCabe MP, Xu $\mathrm{Y}$. Body dissatisfaction, engagement in body change behaviors and sociocultural influences on body image among Chinese adolescents. Body Image. 2010; 7:156-164. doi: 10.1002/erv.900

21. Kolbe RH, Albanese PJ. Man to Man: A Content Analysis of Sole-Male Images in Male-Audience Magazines. Int J Advert.1996; 25, 4: 1-20 
22. Yang CF, Jeffrey PG, Pope HG. Male Body Image in Taiwan Versus the West: Yanggang Zhiqi Meets the Adonis Complex. Am J Psychiatry. 2005; 162(2): 263-269. doi: 10.1176/appi.ajp.162.2.263

23. Tiggemann M, Verri A, Scaravaggi S. Body dissatisfaction, disordered eating, fashion magazines, and clothes: A cross-cultural comparison between Australian and Italian young women. International Union of Psychological Science. 2005; 40(5):293-302. doi: 10.1080/00207590444000311

24. Williams LK, Ricciardelli LA, McCabe MP, Swinburn BA, Waqa GG, Bavadra K. A comparison of the sources and nature of body image messages perceived by Indigenous Fijian and European Australian adolescent girls. Sex Roles.2006; 55: 555-566. doi: 10.1111/j.1467-789X.2011.00922.x

25. Toriola AL, Dolan BM, Evans C, Adetimole O. Weight satisfaction of Nigerian women in Nigeria and Britain: Intergenerational and cross-cultural influences. Eur Eat Disord Rev. 1996; 4(2): 84-94. doi: 10.1002/(SICI)1099-0968(199606)4:2<84::AIDERV148>3.0.CO;2-W

26. Groesz LM, Levine MP, Murnen SK. The effect of experimental presentation of thin media images on body satisfaction: A meta-analytic review. Int J Eat Disord. 2002; 31(1):1-16. doi: 10.1002/ eat.10005

27. Stice E, Schupak-Neuberg E, Shaw HE, Stein RI. Relation of media exposure to eating disorder symptomology: an examination of mediating mechanisms. J Abnorm Psychol. 1994; 103(4), 836-840. doi: $10.1037 / 0021-843 \mathrm{X}$

28. Davidson D, Thill ADW, Lash D. Male and female body shape preferences of young children in the United States, mainland China, and Turkey. Child Study. 2002; 32(3):131-143

29. Abdollahi P, Mann T. Eating disorder symptoms and body image concerns in Iran: Comparisons between Iranian women in Iran and in America. Int J Eat Disord. 2001; 30(3):259-268. doi: 10.1002/ eat.1083

30. Soh NL, Touyz SW, Surgenor LJ. Eating and Body Image Disturbances Across Cultures: Eur Eat Disord Rev. 2006; 14: 54-5. doi: $10.1002 /$ erv.678
31. Wildes JE, Emergy RE,Simons AD. The roles of ethnicity and culture in the development of eating disturbance and body dissatisfaction: A meta-analytic review. Clin Psychol Rev. 2001; 24:521551. doi: 10.1016/S0272-7358(99)00071-9

32. Grabe S,Hyde JS, "Ethnicity and body dissatisfaction among women in the United States: a meta-analysis," Psychol Bull. 2006; 132(4): 622-640. doi: 10.1037/0033-2909.132.4.622

33. Powell AD,Kahn AS. "Racial differences in women's desires to be thin," Int I Eat Disord. 1995; 17(2):191195. doi: 10.1002/1098-108X(199503)17:2<191::AIDEAT2260170213>3.0.CO;2-Z

34. Flynn KJ, Fitzgibbon M. "Body images and obesity risk among Black females: a review of the literature," Ann Behav Med. 1998;20(1):13-24. doi: 10.1007/BF02893804

35. Cachelin FM, Rebeck RM, Chung GH, Pelayo E. "Does ethnicity influence body-size preference? a comparison of body image and body size," Obes Res. 2002; 10(3): 158- 166. doi: 10.1038/ oby. 2002.25

36. David MG,Cooke AK. Focuses on body image; Satisfaction with appearance; Downturn in disordered eating behaviors; Selfacceptance of body weight and shape; Cultural aspects. Psychol Today. 1994; 27, Issue 5: 9

37. Goodman RJ. Flabless Is Fabulous: How Hispanic and Anglo Women Read and Incorporate the Excessively Thin Body Ideal into Everyday Experience. Journalism \& Mass Communication Quarterly. 2002;79, (3): 712-727. doi: 10.1177/107769900207900311

38. Pompper D, Koenig J. Cross-Cultural-Generational Perceptions of Ideal Body Image: Hispanic Women and Magazine Standards. Journalism \& Mass Communication Quarterly. 2004; 81(1):89-107. doi: 10.1177/107769900408100107

39. Viladrich A, Yeh MC, Bruning N, Weiss R. Do Real Women Have Curves Paradoxical Body Images among Hispanics in New York City. Journal of Immigrant Minority Health.2009; 11(1); 20-28. doi: 10.1007/s10903-008-9176-9 